two mirrors being adjustably clamped together, so that they can be set exactly at right angles to one another. Now let them be placed so that their line of contact is inclined $45^{\circ}$ to the horizon, while (in a roughly approximate sense) the vertical plane through that line of contact bisects externally the angle between the mirrors. Vertical lines imaged by successive reflection at the two mirrors will thus appear horizontal, and conversely.

In the case of an echelon grating, the train would bear a general resemblance to a Littrow spectroscope. The light would pass successively through a slit (shortened to a minute square), an objective, and an echelon, and after reflection at the mirrors would return through the echelon and objective, and be brought to a focus in the plane of the slit. For the full advantage of crossed dispersions to be thus realised, it is, of course, essential that the effective aperture of the echelon should be at least as high as it is wide, the width being measured parallel to the dispersion. In echelon gratings and Lummer-Gehrcke plates this generally holds good, though in many gratings the length of the rulings is insufficient for the corresponding condition to be satisfied.

The pair of mirrors described might be replaced by an accurately right-angled prism, with reflecting faces meeting in as sharp and clean a line as possible.

The suggested arrangement may be modified by allowing the beam to pass through a second objective and be brought to a focus in the usual way. A small right-angled prism can then be used to return the beam through the lenses and the echelon between them, and since the intersection of its reflecting faces should lie strictly in the plane of the first formed (singly dispersed) spectrum, it is easy to arrange so that this intersection, as finally viewed, is to one side of the useful field. In thise case the prism need not be accurately right-angled, nor indeed is any great demand made on its other optical qualities; it may be some set-off against this that four transmissions through object-glasses are involved.

If an echelon grating of reflecting type is to be crossed with its own dispersion, a method essentially similar to the last-mentioned modification can be used. The apparatus, as arranged for single dispersion, having been auto-collimated, the beam would in the present case be twice brought to a focus, and would in all pass four times through one and the same obiective.

Boar's Hill, Oxford, December 7 .

Petrifactions of the Earliest European Angiosperms.

UNTIL the three specimens from the English Aptian in the British Museum were recognised as Angiosperms and described in my paper (Phil. Trans. Roy. Soc., series B, vol. cciii., pp. 75-100, plates v-viii, and kindly reviewed in Nature, August 22, p. 641), Angiosperms were supposed not to have existed in northern Europe at that early date. Those three specimens came from two different localities, which minimised the chances of error, but it is highly satisfactory to have to record the discovery of another specimen from a new locality.

The new specimen is from the Lower Greensand of Kent, and belongs to the Maidstone Museum. While pursuing my study of the Lower Cretaceous flora I recently visited the Maidstone Museum, which has the best extant collection of Lower Greensand fossil plants from Mr. W. H. Bensted's famous Iguanodon Quarry. The collection includes a number of large pieces of silicified wood from other of the numerous quarries in the Lower Greensand in the district. All these 1 examined carefully, and the majority of pieces NO. $225 \mathrm{I}$, VOL. 90l proved to be Gymnospermic, but one of the large bits of petrified wood arrested attention. Mr. Allchin, the present curator of the museum, generously allowed me to have sections cut from it, which prove the specimen to be a portion of the trunk of a large woody Angiosperm. A detailed and illustrated account of its anatomy will follow in due course, but it may be remarked here that its general characters differ from those of the three other described species from this horizon, and it certainly represents a new species and possibly a new genus.

As the question of the origin of Angiosperms is one in the forefront of controversy at present, and is one, moreover, about which we have so remarkably little evidence, the discovery of this, which is only the fourth specimen of Aptian Angiosperms yet obtained from northern Europe, is satisfactory in confirming the conclusions reached from the study of the three British Museum specimens.

Marie C. Stopes.

\section{Smoke Trace of Compound Vibrations of Tuning-fork.}

I READ with interest the note by Mr. F. H. Parker on upper partials of a tuning-fork, which appeared in NATURE of November 28 , p. $36 \mathrm{r}$.

As an alternative to taking the first upper partial to be 6.6 times the frequency of the prime, or confirming the relation by separate traces, may I suggest the plan of making a trace of the vibration compounded of the two?

The accompanypanying print is from one corner of a smoke trace used by me at a popular lecture in Igor. One curve shows the fundamental (I28 per second), another the first upper partial, while the centre curve of the three shows the form of vibra$t$ i o $n$ executed when the first upper partial is sounding, together with the prime.

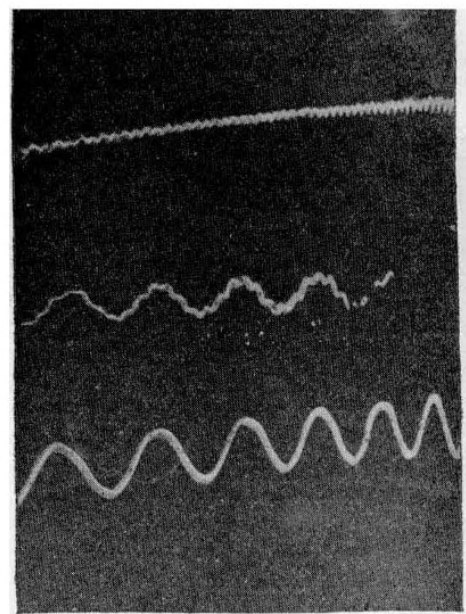

The three sounds

may be heard by the audience, and the smoke traces of each obtained in their presence, and then projected by the lantern. The compound vibration is easily obtained by striking the fork on a hard surface, such as a counter, and so presents no difficulty whatever. The ratio of frequencies of first upper partial and prime for the rather slender fork in question is seen to be of the order $6{ }^{\circ} 25$. E. H. BARTON.

University College, Nottingham, December 7 .

\section{BREATH FIGURES.}

$A^{T}$ intervals during the past year I have tried a good many experiments in the hope of throwing further light upon the origin of these figures, especially those due to the passage of a small blow-pipe flame, or of hot sulphuric acid, across the surface of a glass plate on which, before treatment, the breath deposits evenly. The even 